ORL

\title{
Early-Onset Postirradiation Sarcoma of the Tongue after Pseudotumor Phase
}

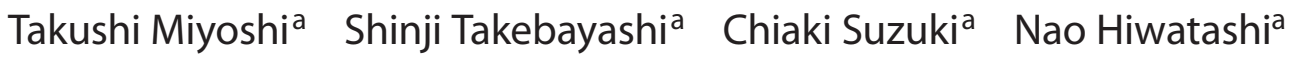 \\ Hiroki lkeda ${ }^{a}$ Kazuo Ono ${ }^{b}$ Makoto Miura ${ }^{a}$ \\ Departments of a Otolaryngology and ${ }^{\mathrm{b}}$ Pathology, Japanese Red Cross Society, Wakayama Medical Center, \\ Wakayama, Japan
}

\section{Key Words}

Radiation · Postirradiation sarcoma • Pseudotumor •

Leiomyosarcoma

\begin{abstract}
Radiation-induced sarcoma usually develops after an interval of more than 10 years from the completion of radiation therapy to the diagnosis of secondary sarcoma. However, the theory of radiation-induced transformation does not rule out postirradiation sarcomas with a short latency period. We experienced the case of a patient with postirradiation leiomyosarcoma of the tongue, which occurred 19 months after he had received chemoradiotherapy. Besides the short latency period, a pseudotumor stage developed between the time of radiation exposure and the development of leiomyosarcoma. In this article, we also describe an immunohistochemical approach to diagnose leiomyosarcoma and the efficacy of a gemcitabine and docetaxel regimen.
\end{abstract}

Copyright $\odot 2011$ S. Karger AG, Base

\section{Introduction}

Radiation-induced sarcoma usually develops after an interval of more than 10 years from the completion of radiation therapy to the diagnosis of secondary sarcoma. The criteria for identifying postirradiation sarcoma were first proposed by Cahan et al. [1] and later modified by Arlen et al. [2]. The criteria include a latency period of several years. Although early-onset postirradiation sarcomas rarely occur, radiation-induced transformation can occur after a short latency period. Indeed, several cases of postirradiation sarcoma occurred within 3 years after exposure to radiation [3-5]. On the other hand, radiation-induced pseudotumor develops earlier than sarcoma, and the median latent period is 79 months [6]. Although both sarcoma and pseudotumor can be induced by radiation, it is still unclear whether pseudotumor represents the precursor stage of sarcoma.

In this article, we describe the case of a patient with postirradiation sarcoma of the tongue, which developed 19 months after radiation exposure. Besides the short latency period of the disease, a pseudotumor developed between the time of radiation exposure and the development of the leiomyosarcoma. Here, we also describe an immunohistological approach to diagnose leiomyosarcoma and refer to the expression of CD117 (KIT), a theoretical therapeutic target of postirradiation sarcoma.

\section{Case Report}

A 63-year-old man visited our outpatient clinic with the complaint of an elevated lesion on the left side of his tongue. He had a familial history of cancer; his grandfather had lung cancer, and his father gastric cancer. On the basis of the results of the biopsy

\section{KARGER}

Fax +4161306 1234 E-Mail karger@karger.ch www.karger.com
(C) 2011 S. Karger AG, Basel

0301-1569/11/0734-0201\$38.00/0

Accessible online at:

www.karger.com/orl
Takushi Miyoshi, MD

Department of Otolaryngology, Japanese Red Cross Society

Wakayama Medical Center, 4-20 Komatsubaradori

Wakayama 640-8558 (Japan)

Tel. +81 73422 4171, E-Mail miyoshi-kyt@umin.ac.jp 


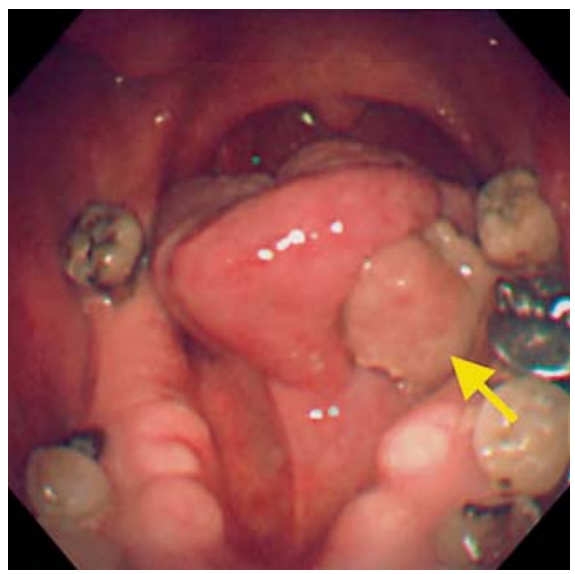

Fig. 1. A smooth tumor (arrow) appeared 19 months after radiation therapy for tongue squamous cell carcinoma. The tumor was resected and diagnosed as a leiomyosarcoma.

examination, he was diagnosed with well-differentiated squamous cell carcinoma. He underwent concurrent external-beam chemoradiotherapy; he received a total dose of $60 \mathrm{~Gy}$ on the left side of his tongue and received chemotherapy consisting of 5-fluorouracil and nedaplatin at a dose of $600 \mathrm{mg} / \mathrm{m}^{2}(1,000 \mathrm{mg} / \mathrm{kg}$ body weight) and $70 \mathrm{mg} / \mathrm{m}^{2}$ (120 mg/ $\mathrm{kg}$ body weight), respectively. Biopsy examination performed after chemoradiotherapy showed no evidence of malignancy.

Fifteen months later, he complained of an elevated lesion in the same region. The elevated lesion on the left side of his tongue was resected with an adequate safety margin; this lesion was diagnosed as an inflammatory pseudotumor on the basis of the results of histopathological examination. The tumor consisted of spindle cells without apparent malignancy. After 4 months of observation, regrowth of the lesion was observed (fig. 1). The tumor was resected again and diagnosed histopathologically as a leiomyosarcoma. Both intraoperative rapid and postoperative pathological reports showed negative margins. Hematoxylin and eosin staining of the tumor showed granulation and an interstitial tissue component (fig. 2a) as well as a leiomyosarcoma component (fig. 2b, c). Histopathological examination of both the pseudotumor and the leiomyosarcoma showed a similar histological picture and proliferation of spindle cells; however, mitosis was significantly enhanced in the leiomyosarcoma compared to the pseudotumor. The results of immunohistochemical staining of the leiomyosarcoma component were positive for $\alpha$-smooth muscle actin and vimentin (fig. 3a, b), partially positive for caldesmon (fig. 3c) and negative for muscle-specific actin, pancytokeratin, S-100 protein or CD56. Furthermore, the results were slightly positive for CD117/KIT (fig. 3d). These findings confirmed the diagnosis.

Although the tumor was resected with free margins, the poor prognosis of this sarcoma warranted administration of an adjuvant chemotherapy consisting of gemcitabine (day 1) and docetaxel (days 1 and 8). The patient received gemcitabine at a dose of 700 $\mathrm{mg} / \mathrm{m}^{2}(1,200 \mathrm{mg} / \mathrm{kg}$ body weight) on day 25 after the operation. Although administration of gemcitabine and docetaxel was planned on day 31 after the operation, it was postponed because he developed severe neutropenia and thrombocytopenia. Subsequently, he recovered from the adverse events and was administered gemcitabine and docetaxel at a dose of $700 \mathrm{mg} / \mathrm{m}^{2}(1,200$ $\mathrm{mg} / \mathrm{kg}$ body weight) and $50 \mathrm{mg} / \mathrm{m}^{2}$ (90 mg/ $\mathrm{kg}$ body weight) on day 55 after the operation. Local recurrence and multiple lung metastases were detected 4 months after the operation. Therefore, he received additional chemotherapy with gemcitabine and docetaxel. After 5 courses of chemotherapy, local recurrence disappeared and lung metastases became significantly reduced in size. Positron emission tomography showed no incorporation of ${ }^{18} \mathrm{~F}$-labeled fluorodeoxyglucose into the sites of local recurrence or lung metastases, and complete response was achieved. Adverse effects of the therapy, i.e. neutropenia (grade 3) and thrombocytopenia (grade 2), were noted. The therapeutic course is summarized in figure 4 .

\section{Discussion}

Retrospective studies show that postirradiation sarcomas usually develop after a long latency period. Indeed, a review of reports on postirradiation sarcoma showed that the median interval from the completion of radiation therapy to the diagnosis of secondary sarcoma is 13.2 years [7]. The latency period of this case was 19 months, which was shorter than what is usually observed. The incidence of postirradiation sarcoma after head-and-neck radiation therapy is reported to be $0.70 \%$ [8]. Although, to our knowledge, there is no report describing the true incidence of early-onset postirradiation sarcoma, it is speculated that those cases are more uncommon. Reported cases of postirradiation sarcoma in the head and neck regions within 3 years after radiation therapy are listed in table $1[3-5]$.

According to the criteria for identifying postirradiation sarcoma established by Arlen et al. [2], postirradiation sarcoma arises from the region exposed to radiation after a latency period of several years. The latency period of our case was 19 months, which was notably shorter than that specified in the criteria. However, on the basis of the results of a biopsy examination performed before chemoradiotherapy, our patient was diagnosed with only squamous cell carcinoma, containing no component of leiomyosarcoma. Furthermore, a biopsy examination performed after the chemoradiotherapy showed no evidence of malignancy. Considering that leiomyosarcoma is a rare disease, it seems appropriate to conclude that leiomyosarcoma was induced by chemoradiotherapy.

Radiotherapy and chemotherapy are themselves carcinogenic. The relative risk of lung cancer increases after chemotherapy [9], whereas that of breast cancer increases 

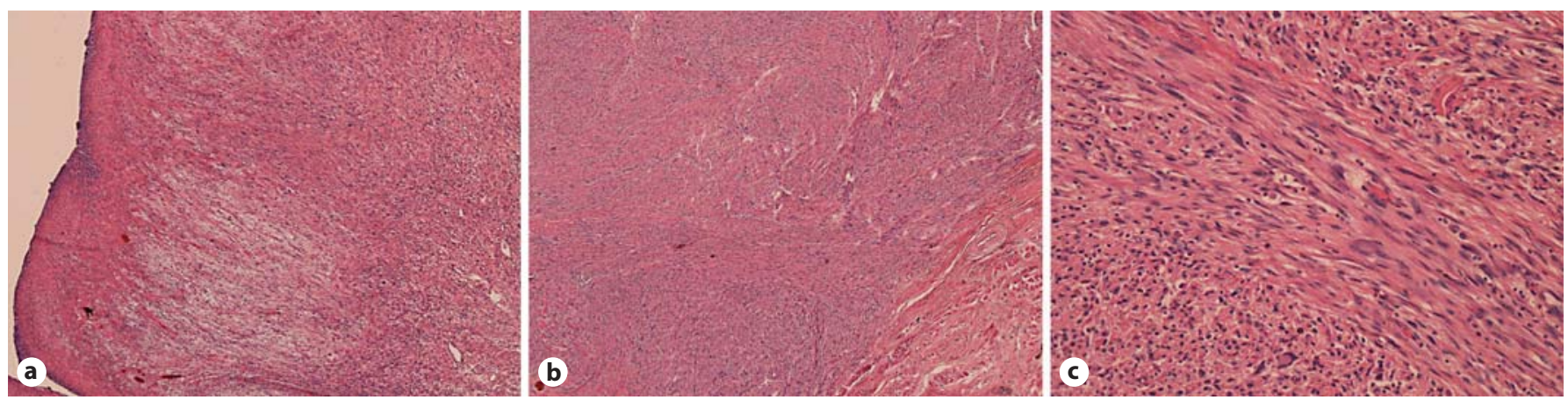

Fig. 2. The tumor comprises diffuse spindle cells. No component of squamous cell carcinoma can be seen. a Granulation and interstitial tissue component. Hematoxylin-eosin. $\times 100$. b, c Leiomyosarcoma component. Hematoxylin-eosin. $\times 100$ and $\times 200$.
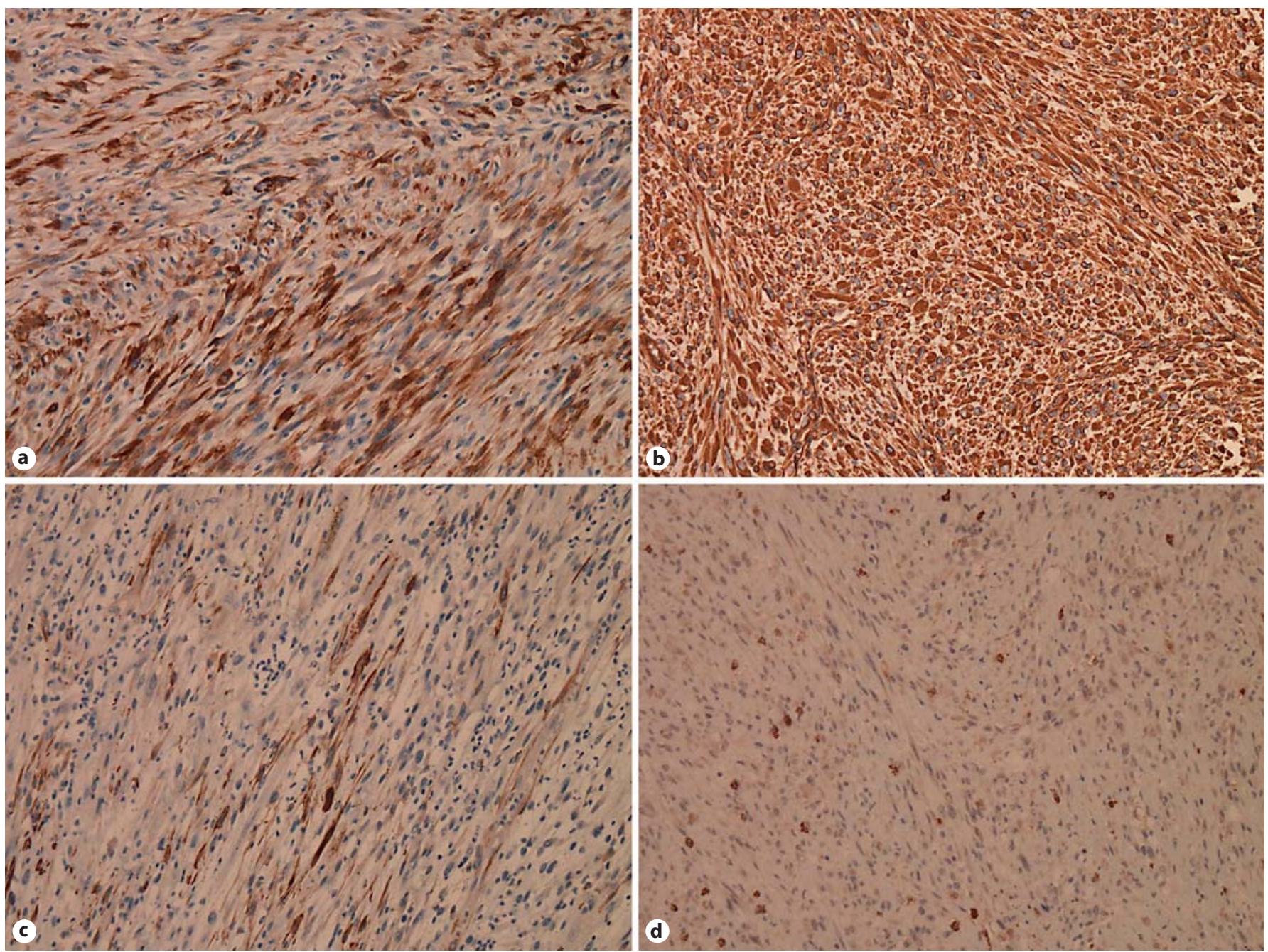

Fig. 3. a, b Positive results for smooth-muscle-specific components, $\alpha$-smooth muscle and vimentin. $\times 200$. c Partially positive results for caldesmon, calmodulin-binding protein. $\times 200$. d Slightly positive results for KIT, tyrosine kinase receptor of cytokine stem cell factor. Mast cells are densely stained. $\times 200$. 
Fig. 4. Summary of the therapeutic course. Initial chemoradiotherapy, operations and adjuvant chemotherapy are shown. 5-FU = 5-Fluorouracil; $\mathrm{OP}=$ operation; $\mathrm{POD}=$ postoperative day.

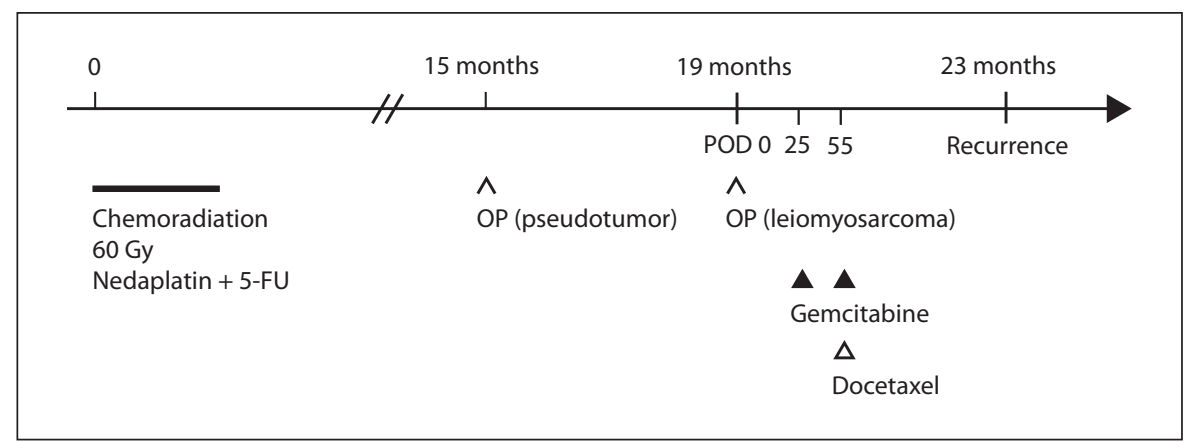

Table 1. Cases of postirradiation malignant neoplasms that occurred within 3 years after radiation in the head and neck region

\begin{tabular}{lllll}
\hline Author, year & Cases & Site & Latency & Pathology \\
\hline Mark et al. [4], 1994 & 1 & mandible & 3 months & osteogenic sarcoma \\
\hline Johns et al. [3], 2002 & 2 & larynx & 1-2 years & leiomyosarcoma, malignant fibrous histiocytoma \\
\hline Chen et al. [5], 2008 & 2 & palate, buccal mucosa & $9-25$ months & rhabdomyosarcoma, sarcoma (histology not specified) \\
\hline
\end{tabular}

after radiation therapy $[10,11]$. A previous report describing approximately 33 postirradiation leiomyosarcoma cases and several other case reports state that postirradiation leiomyosarcoma is associated with chemotherapy, especially with alkylating agents [12]. Concurrent administration of chemotherapy, especially with nedaplatin, may have contributed to the shorter latency period in our patient.

The carcinogenicity of radiation therapy is probably attributable to genomic instability. Mutations in tumor suppressor genes such as TP53 induce early-onset postirradiation sarcoma [13]. Familial accumulation of malignant neoplasm in this patient may suggest genomic instability induced by radiation and may contribute to the short latency period.

A radiation-induced pseudotumor is also known as a radiation-induced inflammatory change, a radiation-induced pseudomass and an inflammatory pseudotumor. A radiation-induced pseudotumor is considered to be a rare complication, according to a retrospective study on radiation therapy for oral squamous cell carcinoma, the prevalence of which was found to be $0.02 \%$ [6]. Although the median latent period of a pseudotumor is 79 months and is shorter than that of postirradiation sarcoma [6], the latency period in our patient is shorter than what is usually observed. It is unknown whether postirradiation sarcoma tends to occur in patients with a pseudotumor.
In this case, pseudotumor and leiomyosarcoma showed a similar histological picture, but the rate of proliferation was greater in the leiomyosarcoma than in the pseudotumor. The existence of the pseudotumor phase implies that this leiomyosarcoma acquired malignant properties in a stepwise manner.

The prognosis of postirradiation sarcoma is poor, and the 5 -year survival rate is less than $30 \%$, as previously reported [7]. Surgical resection is often the mainstay for cure. Although recurrence is frequently observed, additional radiation therapy is rarely administered because of the limited maximum cumulative dose tolerated by the organs. Surgery was performed in our patient, and adjuvant chemotherapy was administered because of poor prognosis.

Chemotherapy regimens, including doxorubicin and ifosfamide such as IFOVADEC, are used for the treatment of patients with postirradiation sarcoma [14]. However, advanced soft-tissue sarcomas are usually resistant to cytotoxic agents such as doxorubicin and ifosfamide. According to the results of a retrospective analysis, patients with leiomyosarcoma showed a better response to the docetaxel and gemcitabine regimen than to the other chemotherapy regimens; moreover, the docetaxel and gemcitabine regimen improved survival in these patients [15]. Although adherence to the docetaxel and gemcitabine regimen as adjuvant chemotherapy did not prevent lo- 
cal recurrence and lung metastases, our patient completely responded to 5 courses of the chemotherapy after tumor recurrence and did not develop severe complications.

We also performed immunostaining to determine the expression of KIT (CD117). KIT receptor tyrosine kinase is reported to be expressed in patients with postirradiation angiosarcoma. A retrospective study on postirradiation sarcoma showed that KIT was expressed in 14 of 16 patients [16]. In the case of our patient, the results were slightly positive for KIT. Imatinib mesylate is an effective treatment for metastasized gastrointestinal stromal tumors. Imatinib mesylate may be an effective regimen for lung metastases in our patient.

\section{Disclosure Statement}

The authors report no financial disclosure or conflict of interest.

\section{References}

1 Cahan WG, Woodard HQ, et al: Sarcoma arising in irradiated bone: report of 11 cases. Cancer 1948;1:3-29.

$\checkmark 2$ Arlen M, Higinbotham NL, Huvos AG, Marcove RC, Miller T, Shah IC: Radiationinduced sarcoma of bone. Cancer 1971;28: 1087-1099.

3 Johns MM, Concus AP, Beals TF, Teknos TN: Early-onset postirradiation sarcoma of the head and neck: report of three cases. Ear Nose Throat J 2002;81:402-406.

4 Mark RJ, Poen J, Tran LM, Fu YS, Selch MT, Parker RG: Postirradiation sarcomas: a single-institution study and review of the literature. Cancer 1994;73:2653-2662.

$\checkmark 5$ Chen YW, Tu HF, Wu TH, Lo WL, Chang CS, Chang KW, Kao SY: Sarcomas and sarcomatoid tumor after radiotherapy of oral squamous cell carcinoma: analysis of 4 cases. Oral Surg Oral Med Oral Pathol Oral Radiol Endod 2008;105:65-71.

6 Oota S, Shibuya H, Hamagaki M, Yoshimura R, Iwaki H, Kojima M, Takagi M: Oral pseudotumor: benign polypoid masses following radiation therapy. Cancer 2003;97:13531357.
7 Wiklund TA, Blomqvist CP, Raty J, Elomaa I, Rissanen P, Miettinen M: Postirradiation sarcoma: analysis of a nationwide cancer registry material. Cancer 1991;68:524-531.

-8 Van der Laan BF, Baris G, Gregor RT, Hilgers FJ, Balm AJ: Radiation-induced tumours of the head and neck. J Laryngol Otol 1995;109: 346-349.

-9 Swerdlow AJ, Douglas AJ, Hudson GV, Hudson BV, Bennett MH, MacLennan KA: Risk of second primary cancers after Hodgkin's disease by type of treatment: analysis of 2,846 patients in the British National Lymphoma Investigation. BMJ 1992;304:11371143.

10 Van Leeuwen FE, Klokman WJ, Hagenbeek A, Noyon R, van den Belt-Dusebout AW, van Kerkhoff EH, van Heerde P, Somers R: Second cancer risk following Hodgkin's disease: a 20-year follow-up study. J Clin Oncol 1994; 12:312-325.

11 Bhatia S, Robison LL, Oberlin O, Greenberg M, Bunin G, Fossati-Bellani F, Meadows AT: Breast cancer and other second neoplasms after childhood Hodgkin's disease. N Engl J Med 1996;334:745-751.

-12 Brockstein B, Mundt A, Haraf DJ, Ferguson M, Montag A: Radiation-induced leiomyosarcoma: does antimetabolite chemotherapy contribute? A report of three cases. Sarcoma 2003; 7:167-172.
13 Salmon A, Amikam D, Sodha N, Davidson S, Basel-Vanagaite L, Eeles RA, Abeliovich D, Peretz T: Rapid development of post-radiotherapy sarcoma and breast cancer in a patient with a novel germline 'de-novo' tp53 mutation. Clin Oncol (R Coll Radiol) 2007; 19:490-493.

14 Aoki T, Ozeki Y, Watanabe M, Tanaka S, Isaki H, Terahata S: Development of primary leiomyosarcoma of the sternum postirradiation: report of a case. Surg Today 1998;28: 1326-1328.

15 Bay JO, Ray-Coquard I, Fayette J, Leyvraz S, Cherix S, Piperno-Neumann S, Chevreau C, Isambert N, Brain E, Emile G, Le Cesne A, Cioffi A, Kwiatkowski F, Coindre JM, Bui NB, Peyrade F, Penel N, Blay JY: Docetaxel and gemcitabine combination in 133 advanced soft-tissue sarcomas: a retrospective analysis. Int J Cancer 2006;119:706-711.

$\checkmark 16$ Komdeur R, Hoekstra HJ, Molenaar WM, van den Berg E, Zwart N, Pras E, PlazaMenacho I, Hofstra RM, van der Graaf WT: Clinicopathologic assessment of postradiation sarcomas: KIT as a potential treatment target. Clin Cancer Res 2003;9:2926-2932. 


\section{Erratum}

In the paper 'Early-Onset Postirradiation Sarcoma of the Tongue after Pseudotumor Phase' by Miyoshi et al. [ORL 2011;73:201-205] the unit ' $\mathrm{mg} / \mathrm{kg}$ body weight' is incorrect. The correct unit should be 'mg/body'.

The following sentences should now read:

He underwent concurrent external-beam chemoradiotherapy; he received a total dose of $60 \mathrm{~Gy}$ on the left side of his tongue and received chemotherapy consisting of 5-fluorouracil and nedaplatin at a dose of $600 \mathrm{mg} / \mathrm{m}^{2}(1,000 \mathrm{mg} /$ body $)$ and $70 \mathrm{mg} / \mathrm{m}^{2}(120 \mathrm{mg} /$ body), respectively.

The patient received gemcitabine at a dose of $700 \mathrm{mg} / \mathrm{m}^{2}(1,200 \mathrm{mg} / \mathrm{body})$ on day 25 after the operation.

Subsequently, the recovered from the adverse events and was administered gemcitabine and docetaxel at a dose of $700 \mathrm{mg} / \mathrm{m}^{2}(1,200 \mathrm{mg} /$ body $)$ and $50 \mathrm{mg} / \mathrm{m}^{2}$ (90 mg/body) on day 55 after the operation. 